\title{
Risk management standards for project management
}

\author{
Petr Rehacek* \\ Department of Systems Engineering, Faculty of Economics, VSB - Technical University, Ostrava, Czech Republic
}

\section{ARTICLE INFO}

\section{Article history:}

Received 24 January 2017

Received in revised form

23 April 2017

Accepted 25 April 2017

\section{Keywords:}

Management

Project

Risk

\begin{abstract}
A B S T R A C T
The purpose of this paper is to present and compare the main standards for project risk management that are currently available today. Four international standards recognized world-wide were selected for comparison: PMI, PRINCE2, IPMA, ISO 31000 and IEC 62198. Project management has evolved over recent years into a mature professional discipline characterized by a formalized body of knowledge and the definition of systematic processes for the execution of a project. All these and possibly other factors as well, have resulted in growing numbers of books, articles and conferences being devoted to project risk management. This level of activity has also led to the development of a number of standards that prescribe for and advise organizations on the best way to manage their risks. Every meaningful standard for project management contains project risk management as its important part.
\end{abstract}

(C) 2017 The Authors. Published by IASE. This is an open access article under the CC BY-NC-ND license (http://creativecommons.org/licenses/by-nc-nd/4.0/).

\section{Introduction}

Risk is present in our everyday life and risk management is universal but in most circumstances an unstructured activity, based on common sense, relevant knowledge, experience and instinct. Chapter 1 introduces the article, basic principles and concepts of risk management. Chapter 2 consists of brief recapitulation of the selected standards in a manner that facilitates their comparison. This is followed by a comparison in chapter 3 including discussion regarding the commonalities among the standards. Chapter 4 contains the conclusion.

Risk management is defined as coordinated activities to direct and control an organization with regard to risk (ISO, 2009). Based on this definition, project risk management can be derivatively defined as coordinate activities to direct and control a project with regard to risk. Project risk management is not an optional activity: it is essential to successful project management. It should be applied to all projects and be included in project plans and operational documents. In this way, it becomes an integral part of every aspect of managing the project.

Project Risk Management addresses the uncertainty in project estimates and assumptions. Therefore, it builds upon and extends other project management processes. There is a paradox about

\footnotetext{
* Corresponding Author.

Email Address: perehacek@gmail.com

https://doi.org/10.21833/ijaas.2017.06.001

2313-626X/C) 2017 The Authors. Published by IASE.

This is an open access article under the CC BY-NC-ND license

(http://creativecommons.org/licenses/by-nc-nd/4.0/)
}

project risk that affects most projects. In the early stages of a project, the level of risk exposure is at its maximum but information on the project risks is at a minimum. This situation does not mean that a project should not go forward because little is known at that time. Rather, there may be different ways of approaching the project that have different risk implications. The more this situation is recognized, the more realistic the project plans and expectations of results will be. Although wording of definition of the term risk varies (Table 1), it always contains uncertainty and effect on objectives.

As we can see, the definitions are really similar. The main characteristic of the risk is its uncertainty. We simply don't have complete information, but we know what we don't know (Rehacek, 2011; Šviráková and Soukalová, 2015). In case of complete information, there is no uncertainty and therefore no risk - we just have problem to solve or benefit to exploit.

A risk may have one or more causes and, if it occurs, it may have one or more impacts. A cause may be a given or potential requirement, assumption, constraint, or condition that creates the possibility of negative or positive outcomes. Šviráková (2014) uses system dynamics methodology to identify causes and consequences of project risks. The cause, event and effect relationship is shown in Fig. 1.

Organizations perceive risk as the effect of uncertainty on projects and organizational objectives. Organizations and stakeholders are willing to accept varying degrees of risk depending on their risk attitude. The risk attitudes of both the 
organization and the stakeholders may be influenced by a number of factors, which are broadly classified into three themes (PMI, 2013):

- Risk appetite is the degree of uncertainty an entity is willing to take on in anticipation of a reward.

- Risk tolerance is the degree, amount, or volume of risk that an organization or individual will withstand.

- Risk threshold refers to measures along the level of uncertainty or the level of impact at which a stakeholder may have a specific interest. Below that risk threshold, the organization will accept the risk. Above that risk threshold, the organization will not tolerate the risk

Positive and negative risks are commonly referred to as opportunities and threats. The project may be accepted if the risks are within tolerances and are in balance with the rewards that may be gained by taking the risks. Positive risks that offer opportunities within the limits of risk tolerances may be pursued in order to generate enhanced value.

\section{Most Common Standards for Risk Management}

\subsection{PMI}

The Project Management Body of Knowledge is a set of standard terminology and guidelines (a body of knowledge) for project management. The body of knowledge evolves over time and is presented in A Guide to the Project Management Body of Knowledge, a book whose fifth edition came out in 2013. The Guide is a document resulting from work overseen by the Project Management Institute (PMI), which offers the CAPM and PMP certifications.

Most of this subchapter is made up of quotations from PMI (2013) and PMI (2009). PMBOK's Project Risk Management includes the processes of conducting risk management planning, identification, analysis, response planning, and controlling risk on a project. The objectives of project risk management are to increase the likelihood and impact of positive events, and decrease the likelihood and impact of negative events in the project.

Table 1: Risk definitions

\begin{tabular}{cc}
\hline Methodology & Definition \\
\hline PMI & $\begin{array}{r}\text { Project risk is an uncertain event or condition that, if it occurs, has a positive or a negative effect on projects } \\
\text { objectives such as scope, schedule, cost, and quality. }\end{array}$ \\
PRINCE2 & $\begin{array}{r}\text { A risk is an uncertain event or set of events that, should it occur, will have an effect on the achievement of } \\
\text { objectives. It consists of a combination of the probability of a perceived threat or opportunity occurring, and the } \\
\text { magnitude of its impact on objectives. }\end{array}$ \\
IPMA & Precarious event or condition which if it occurs impacts the attainment of the project objective negatively. \\
Ro and IEC & Risk is effect of uncertainty on objectives.
\end{tabular}

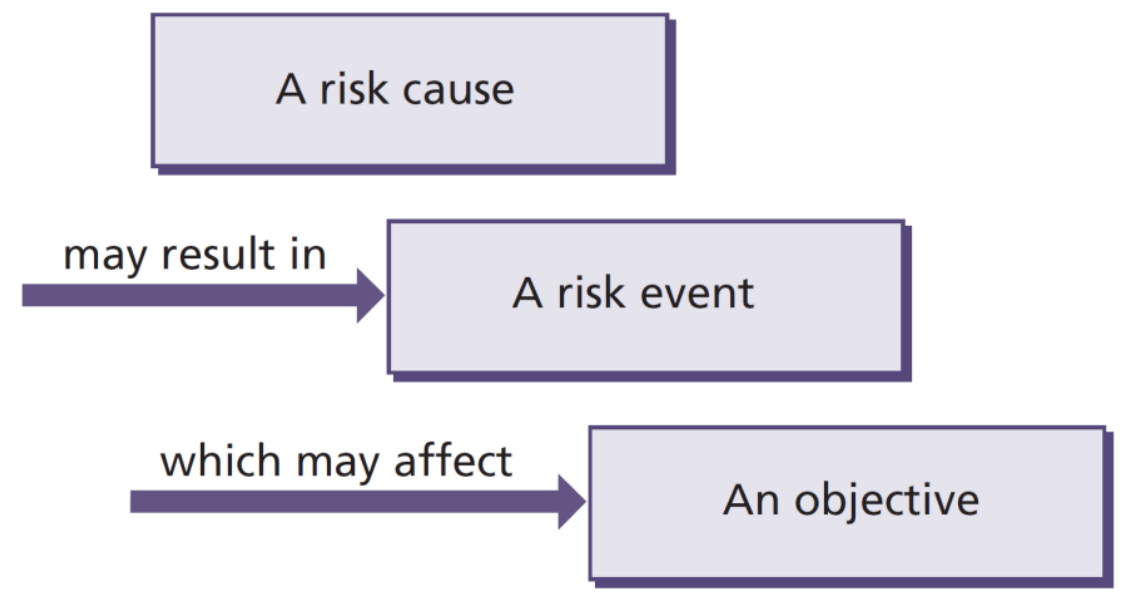

Fig. 1: Risk cause, event and effect (OGC, 2009)

Fig. 2 provides an overview of the Project Risk Management processes, which are as follows:

- Plan Risk Management: The process of defining how to conduct risk management activities for a project.

- Identify Risks: The process of determining which risks may affect the project and documenting their characteristics.

- Perform Qualitative Risk Analysis: The process of prioritizing risks for further analysis or action by assessing and combining their probability of occurrence and impact.

- Perform Quantitative Risk Analysis: The process of numeric analysis of the effect of identified risks on overall project objectives.

- Plan Risk Responses: The process of developing options and actions to enhance opportunities and to reduce threats to project objectives.

- Control Risks: The process of implementing risk response plans, tracking identified risks, monitoring residual risks, identifying new risks, 
and evaluating risk process effectiveness throughout the project.

\subsubsection{Plan risk management}

Plan Risk Management is the process of defining how to conduct risk management activities for a project. The key benefit of this process is it ensures that the degree, type, and visibility of risk management are commensurate with both the risks and the importance of the project to the organization. The risk management plan is vital to communicate with and obtain agreement and support from all stakeholders to ensure the risk management process is supported and performed effectively over the project life cycle.

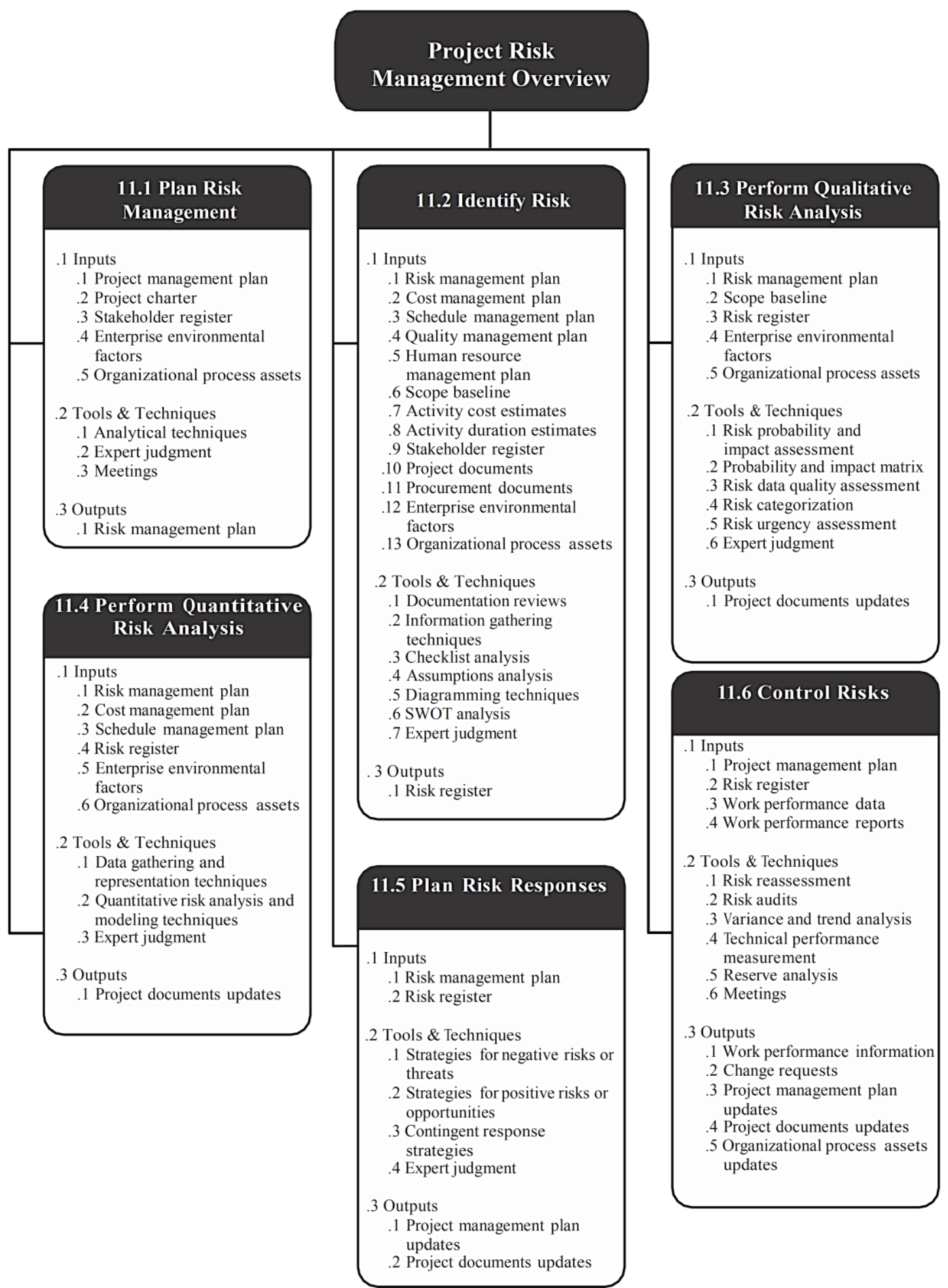

Fig. 2: Project risk management overview (PMI, 2013)

Careful and explicit planning enhances the probability of success for other risk management processes. Planning is also important to provide sufficient resources and time for risk management 
activities and to establish an agreed upon basis for evaluating risks. The Plan Risk Management process should begin when a project is conceived and should be completed early during project planning.

\subsubsection{Identify risks}

Risks identification is the process of determining which risks may affect the project and documenting their characteristics. The key benefit of this process is the documentation of existing risks and the knowledge and ability it provides to the project team to anticipate events.

Identify risks is an iterative process, because new risks may evolve or become known as the project progresses through its life cycle. The frequency of iteration and participation in each cycle will vary by situation. The format of the risk statements should be consistent to ensure that each risk is understood clearly and unambiguously in order to support effective analysis and response development. The risk statement should support the ability to compare the relative effect of one risk against others on the project. The process should involve the project team so they can develop and maintain a sense of ownership and responsibility for the risks and associated risk response actions. Stakeholders outside the project team may provide additional objective information.

A range of tools and techniques is available for risk identification. These fall into the following three categories, as illustrated in Fig. 3.

Historical Review: Historical reviews are based on what occurred in the past, either on this project, or other similar projects in the same organization, or comparable projects in other organizations. Historical review approaches rely on careful selection of comparable situations which are genuinely similar to the current project, and filtering of data to ensure that only relevant previous risks are considered. In each case, the risks identified in the selected historical situation should be considered, asking whether they or similar risks might arise in this project.

Current Assessments: Current assessments rely on detailed consideration of the current project, analysing its characteristics against given frameworks and models in order to expose areas of uncertainty. Unlike historical review approaches, current assessment techniques do not rely on outside reference points, but are based purely on examination of the project.

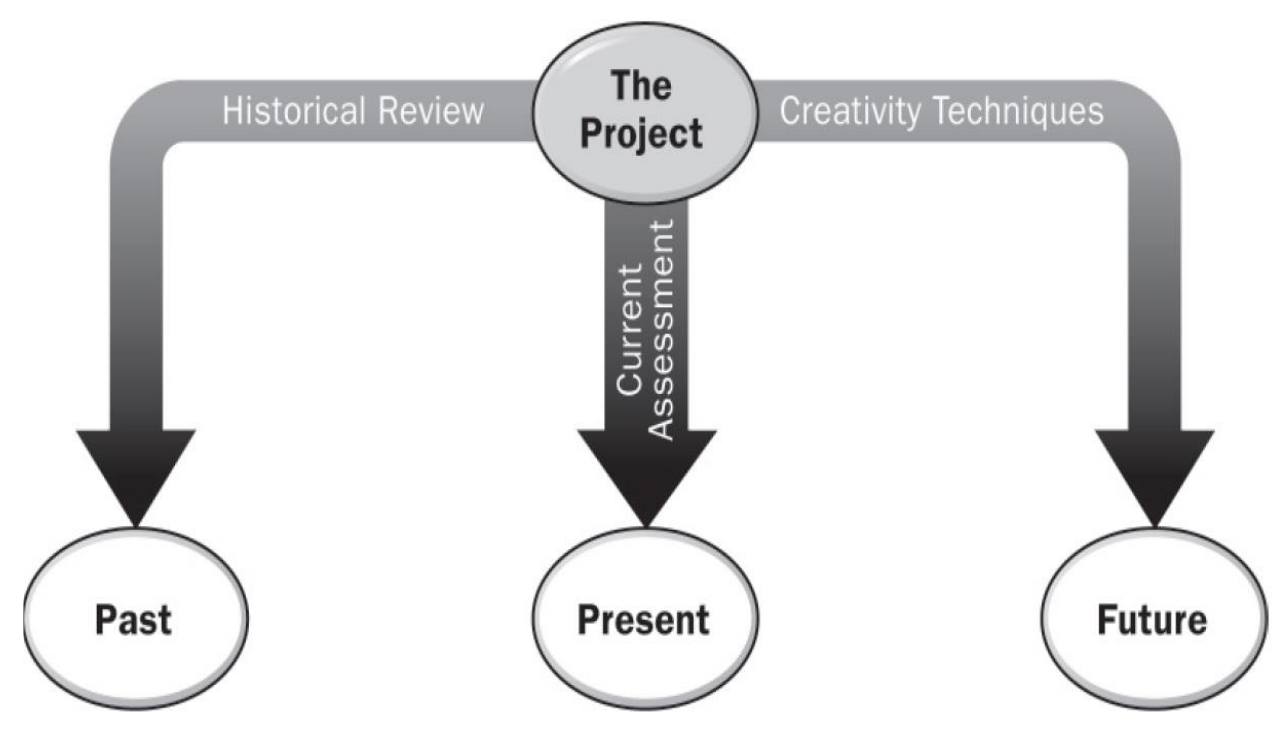

Fig. 3: Three perspectives of risk identification (PMI, 2009)

Creativity Techniques: A wide range of creativity techniques can be used for risk identification, which encourages project stakeholders to use their imagination to find risks which might affect the project. The outcomes or effectiveness of these techniques depend on the ability of participants to think creatively. These techniques can be used either singly or in groups, and employ varying degrees of structure. These techniques depend on the ability of participants to think creatively, and their success is enhanced by use of a skilled facilitator.

Each category of risk identification technique has strengths and weaknesses, and no single technique can be expected to reveal all knowable risks.
Consequently, the Identify Risks process for a particular project should use a combination of techniques, perhaps selecting one from each category. For example, a project may choose to use a risk identification checklist (historical review), together with assumptions analysis (current assessment) and brainstorming (creativity).

The primary output from risk identification is the initial entry into the risk register. The risk register is a document in which the results of risk analysis and risk response planning are recorded. It contains the outcomes of the other risk management processes as they are conducted, resulting in an increase in the level and type of information contained in the risk 
register over time. The preparation of the risk register begins in the risk identification process with the following information, and then becomes available to other project management and risk management processes:

- List of identified risks: The identified risks are described in as much detail as is reasonable. A structure for describing risks using risk statements may be applied, for example, event may occur causing impact, or if cause exists, event may occur leading to effect. In addition to the list of identified risks, the root causes of those risks may become more evident. These are the fundamental conditions or events that may give rise to one or more identified risks. They should be recorded and used to support future risk identification for this and other projects.

- List of potential responses: Potential responses to a risk may sometimes be identified during the risk identification. These responses, if identified, should be used as inputs to planning of the risk responses.

\subsubsection{Perform qualitative risk analysis}

Qualitative Risk Analysis is the process of prioritizing risks for further analysis or action by assessing and combining their probability of occurrence and impact. The key benefit of this process is that it enables project managers to reduce the level of uncertainty and to focus on high-priority risks.

Qualitative risk analysis assesses the priority of identified risks using their relative probability or likelihood of occurrence, the corresponding impact on project objectives if the risks occur, as well as other factors such as the time frame for response and the organizations risk tolerance associated with the project constraints of cost, schedule, scope, and quality. Such assessments reflect the risk attitude of the project team and other stakeholders. Effective assessment therefore requires explicit identification and management of the risk approaches of key participants.

Establishing definitions of the levels of probability and impact can reduce the influence of bias. The time criticality of risk-related actions may magnify the importance of a risk. An evaluation of the quality of the available information on project risks also helps to clarify the assessment of the risks importance to the project.

Qualitative risk analysis is usually a rapid and cost-effective means of establishing priorities for planning of the risk responses and lays the foundation for Quantitative Risk Analysis, if required. The performance of qualitative risk analysis is performed regularly throughout the project life cycle, as defined in the projects risk management plan. This process can lead into Perform Quantitative Risk Analysis or directly into Plan Risk Responses.
As new information becomes available through the qualitative risk assessment, the risk register is updated. Updates to the risk register may include assessments of probability and impacts for each risk, risk ranking or scores, risk urgency information or risk categorization, and a watch list for low probability risks or risks requiring further analysis.

\subsubsection{Perform quantitative risk analysis}

Perform Quantitative Risk Analysis is the process of numerically analyzing the effect of identified risks on overall project objectives. The key benefit of this process is that it produces quantitative risk information to support decision making in order to reduce project uncertainty.

Perform Quantitative Risk Analysis is performed on risks that have been prioritized by the Perform Qualitative Risk Analysis process as potentially and substantially impacting the projects competing demands. The Perform Quantitative Risk Analysis process analyzes the effect of those risks on project objectives. It is used mostly to evaluate the aggregate effect of all risks affecting the project. When the risks drive the quantitative analysis, the process may be used to assign a numerical priority rating to those risks individually.

Perform Quantitative Risk Analysis generally follows the Perform Qualitative Risk Analysis process. In some cases, it may not be possible to execute the Perform Quantitative Risk Analysis process due to lack of sufficient data to develop appropriate models. The project manager should exercise expert judgment to determine the need for and the viability of quantitative risk analysis. The availability of time and budget, and the need for qualitative or quantitative statements about risk and impacts, will determine which method(s) to use on any particular project. Perform Quantitative Risk Analysis should be repeated, as needed, as part of the Control Risks process to determine if the overall project risk has been satisfactorily decreased. Trends may indicate the need for more or less focus on appropriate risk management activities.

Project documents are updated with information resulting from quantitative risk analysis. For example, risk register updates could include:

- Probabilistic analysis of the project.

- Probability of achieving cost and time objectives.

- Prioritized list of quantified risks.

- Trends in quantitative risk analysis results.

\subsubsection{Plan risk responses}

Plan Risk Responses is the process of developing options and actions to enhance opportunities and to reduce threats to project objectives. The key benefit of this process is that it addresses the risks by their priority, inserting resources and activities into the budget, schedule and project management plan as needed. 
In the Plan Risk Responses process, several project documents are updated as needed. For example, when appropriate risk responses are chosen and agreed upon, they are included in the risk register. The risk register should be written to a level of detail that corresponds with the priority ranking and the planned response. Often, the high and moderate risks are addressed in detail. Risks judged to be of low priority are included in a watch list for periodic monitoring.

Strategies for Negative Risks or Threats Three strategies, which typically deal with threats or risks that may have negative impacts on project objectives if they occur, are: avoid, transfer, and mitigate. The fourth strategy is accept, can be used for negative risks or threats as well as positive risks or opportunities. Each of these risk response strategies have varied and unique influence on the risk condition. These strategies should be chosen to match the risks probability and impact on the projects overall objectives. Avoidance and mitigation strategies are usually good strategies for critical risks with high impact, while transference and acceptance are usually good strategies for threats that are less critical and with low overall impact.

Strategies for Positive Risks or Opportunities Three of the four responses are suggested to deal with risks with potentially positive impacts on project objectives: exploit, share, and enhance. The fourth strategy is accept, can be used for negative risks or threats as well as positive risks or opportunities.

\subsubsection{Control risks}

Control Risks is the process of implementing risk response plans, tracking identified risks, monitoring residual risks, identifying new risks, and evaluating risk process effectiveness throughout the project. The key benefit of this process is that it improves efficiency of the risk approach throughout the project life cycle to continuously optimize risk responses.

Planned risk responses that are included in the risk register are executed during the life cycle of the project, but the project work should be continuously monitored for new, changing, and out-dated risks. The Control Risks process applies techniques, such as variance and trend analysis, which require the use of performance information generated during project execution. Other purposes of the Control Risks processes are to determine if:

- Project assumptions are still valid,

- Analysis shows an assessed risk has changed or can be retired,

- Risk management policies and procedures are being followed, and

- Contingency reserves for cost or schedule should be modified in alignment with the current risk assessment.
Control Risks can involve choosing alternative strategies, executing a contingency or fall-back plan, taking corrective action, and modifying the project management plan. The risk response owner reports periodically to the project manager on the effectiveness of the plan, any unanticipated effects, and any correction needed to handle the risk appropriately. Control Risks also includes updating the organizational process assets, including project lessons learned databases and risk management templates, for the benefit of future projects. Implementing contingency plans or workarounds sometimes results in a change request. Change requests can include recommended corrective and preventive actions as well.

If the approved change requests have an effect on the risk management processes, the corresponding component documents of the project management plan are revised and reissued to reflect the approved changes. Project documents that may be updated as a result of the Control Risk process include, but are not limited to the risk register.

\subsection{PRINCE2}

PRINCE2 (OGC, 2009) is a process-based project management approach suitable for any type of project; it is a de facto standard used extensively by the UK public sector and is widely recognized and used in the private sector, both in the UK and internationally. According to PRINCE2 there are six aspects of a project implementation that always need to be controlled: time, scope, costs, benefits, quality and risks (Šviráková, 2014).

PRINCE2s approach to the management of risk is based on OGCs publication Management of Risk: Guidance for Practitioners (OGC, 2009). Most of this subchapter is made up of quotations from this source. PRINCE2's risk management is described by risk theme. This theme addresses how project management manages the uncertainties in its plans and in the wider project environment.

Fig. 4 shows the elements of the risk management procedure: Identify Assess, Plan, Implement and Communicate.

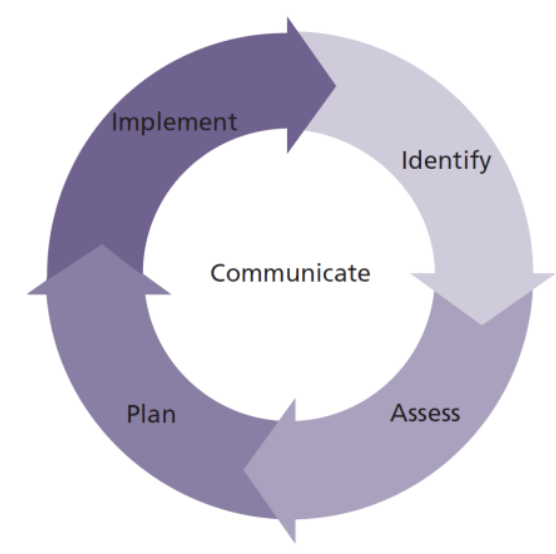

Fig. 4: The risk management procedure according to PRINCE2 (OGC, 2009) 


\subsubsection{Identify (Context and risks)}

Identify context: The primary goal of the Identify context step is to obtain information about the project in order to understand the specific objectives that are at risk and to formulate the Risk Management Strategy for the project. The Risk Management Strategy describes how risks will be managed during the project. It is created during the initiation stage and then reviewed and possibly updated at the end of each stage. The projects Risk Management Strategy should be based on the corporate risk management policy or on the programmes Risk Management Strategy.

Identify risks: The primary goal of the Identify risks step is to recognize the threats and opportunities that may affect the projects objectives.

PRINCE2 recommends the following actions:

- Capture identified threats and opportunities in the Risk Register

- Prepare early warning indicators to monitor critical aspects of the project and provide information on the potential sources of risk

- Understand the stakeholders view of the specific risks captured.

An effective way of identifying risks is to use a risk workshop. This is a group session designed to identify threats and opportunities. The session should be facilitated by someone who is able to use a range of identification techniques, such as those listed in the boxed example. Workshops should lead to the identification of a broad range of risks and possible risk owners.

An important aspect of identifying risks is being able to provide a clear and unambiguous expression of each one. A useful way of expressing risk is to consider the following aspects of each risk:

- Risk cause: This should describe the source of the risk, i.e. the event or situation that gives rise to the risk. These are often referred to as risk drivers. They are not risks in themselves, but the potential trigger points for risk. These may be either internal or external to the project.

- Risk event: This should describe the area of uncertainty in terms of the threat or the opportunity.

- Risk effect: This should describe the impact(s) that the risk would have on the project objectives should the risk materialize.

\subsubsection{Assess (Estimate and evaluate)}

Estimate: The primary goal of the Estimate step is to assess the threats and the opportunities to the project in terms of their probability and impact. The risk proximity will also be of interest to gauge how quickly the risk is likely to materialize if no action were taken. PRINCE2 recommends that the following is understood:
- The probability of the threats and opportunities in terms of how likely they are to occur.

- The impact of each threat and opportunity in terms of the project objectives. For example, if the objectives are measured in time and cost, the impact should also be measured in units of time and cost.

- The proximity of these threats and opportunities with regard to when they might materialize.

- How the impact of the threats and opportunities may change over the life of the project.

Evaluate: The primary goal of the Evaluate step is to assess the net effect of all the identified threats and opportunities on a project when aggregated together. This will enable an assessment to be made of the overall severity of the risks facing the project, to determine whether this level of risk is within the risk tolerance set by the Project Board and whether the project has continued business justification.

\subsubsection{Plan}

The primary goal of the Plan step is to prepare specific management responses to the threats and opportunities identified, ideally to remove or reduce the threats and to maximize the opportunities. Attention to the Plan step ensures as far as possible that the project is not taken by surprise if a risk materializes.

The Plan step involves identifying and evaluating a range of options for responding to threats and opportunities. It is important that the risk response is proportional to the risk and that it offers value for money. A key factor in the selection of responses will be balancing the cost of implementing the responses against the probability and impact of allowing the risk to occur. Any chosen responses should be built into the appropriate level of plan, with a provision made for any fall-back plans.

\subsubsection{Implement}

The primary goal of the Implement step is to ensure that the planned risk responses are actioned, their effectiveness monitored, and corrective action taken where responses do not match expectations.

An important part of the Implement step is to ensure that there are clear roles and responsibilities allocated to support the Project Manager in the management of project risks.

The main roles in this respect are:

- Risk owner: A named individual who is responsible for the management, monitoring and control of all aspects of a particular risk assigned to them, including the implementation of the selected responses to address the threats or to maximize the opportunities

- Risk actionee: An individual assigned to carry out a risk response action or actions to respond to a 
particular risk or set of risks. They support and take direction from the risk owner.

In many cases, the risk owner and risk actionee are likely to be the same person. The risk owner should be the person most capable of managing the risk. Allocating too many risks to any one individual should be avoided.

\subsubsection{Communicate}

Communication is a step that is carried out continually. The Communicate step should ensure that information related to the threats and opportunities faced by the project is communicated both within the project and externally to stakeholders.

\subsection{IPMA}

The IPMA Individual Competence Baseline (ICB) is the global standard for individual competences in project, programme and portfolio management. Most of this subchapter is made up of quotations from IPMA (2015). Risk and Opportunities is one of core project competences in practice competence area.

According to IPMA (2015), risk (negative effects) and opportunity (positive effects) are always viewed in their relation to and consequences for realising the objectives of the project. It is advisable as a first step to consider which overall strategies would best serve the handling of risks and opportunities relative to the corporate strategies and the project in question. After that, the risk and opportunity management process is characterised by first identifying and assessing risks and opportunities, followed by the development and implementation of a response plan covering the intended and planned actions for dealing with identified risks and opportunities. The response plan should be developed and implemented in line with the chosen overall risk and opportunity strategies. The individual is responsible for involving team members and keeping the team committed to the risk and opportunity management process; for making the team alert to risks and opportunities; for involving other stakeholders in the process and for involving the appropriate subject matter experts whenever necessary.

\subsubsection{Develop and implement a risk management framework}

The individual designs, develops and implements a risk management framework in order to ensure that risks and opportunities are managed consistently and systematically throughout the project lifecycle. The risk management framework should include the definition of the methods to be used to identify, categorise, evaluate, assess and treat risks and should link to the organisations risk management policy and international, national or industry standards. When projects are part of a programme or portfolio, the risk management framework also describes who is responsible for handling which risks and opportunities and what kind of escalation paths there are (upwards, downwards, sideways).

\subsubsection{Identify risks and opportunities}

The individual is responsible for the ongoing task of identifying all sources of risks and opportunities and involving others in this process. There are various sources of risks and opportunities, both internal to the project and external. The individual can make use of various techniques and sources to identify risks and opportunities (e.g. from lessons learned, literature, risk and opportunity breakdown structures and interactive sessions with team members, stakeholders and subject matter experts). The identification process is not only about identifying risks, but also about opportunities that could, for instance, make the deliverables cheaper, or make the project run faster, less prone to risks or simply better from a quality perspective. Because the influences coming from the environment of the project do change over time, risk and opportunity identification should be a continuous and ongoing process.

\subsubsection{Assess the probability and impact of risks and opportunities}

The individual is responsible for the ongoing task of assessing identified risks and opportunities. Risk and opportunity assessment can be done qualitatively and quantitatively. The best approach is to do both and to regularly re-assess both risks and opportunities. The qualitative assessment could cover a more in-depth analysis of the sources behind identified risks and/or opportunities; it also deals with conditions and impacts. An example is scenario planning. The quantitative assessment deals with probabilities and estimates and it also translates probabilistic impacts into quantifiable measures. Quantitative assessment provides numerical values measuring probability and impact expected from risks and opportunities.

Monte Carlo analysis and decision trees are examples of powerful quantitative risk assessment techniques.

\subsubsection{Select strategies and implement response plans to address risks and opportunities}

The individual is responsible for the ongoing process of selecting and implementing optimal responses to any identified risk or opportunity. This process entails assessing various possible types of responses and finally selecting the ones that are optimal or most appropriate. For each risk the response options may include: 
- Avoiding the risk by deciding not to start or continue with the activity that gives rise to the risk;

- Accepting or increasing the risk in order to pursue an opportunity;

- Removing the risk source;

- Changing the likelihood;

- Changing the consequences;

- Sharing the risk with another party or parties (including contracts and risk financing);

- Accepting the risk by informed decision;

- Preparing and implementing a contingency plan;

- Similar response options apply to opportunities;

- Eliminating the uncertainty by making the opportunity definitely happen (exploit);

- Allocating ownership to a third party who is best able to handle it (share);

- Increasing probability and/or impact, by identifying and maximising key opportunity drivers (enhance);

- Taking no special measures to address the opportunity (ignore).

Those risks that are not acceptable and those opportunities that are to be pursued require an appropriate response plan. Often, even after implementing risk responses, there is a residual risk that still has to be managed.

\subsubsection{Evaluate and monitor risks, opportunities and implemented responses}

After the appropriate risk and opportunity responses have been implemented (this may include appointing risk owners for certain or all risks) the risks and opportunities will need to be monitored. The risks and opportunities and the appropriateness of the selected responses should be re-assessed periodically. Risk and opportunity probabilities and/or impacts may change, new information may become available, new risks and opportunities may arise and the responses may no longer be appropriate. The overall strategies may also need to be evaluated. In fact, risk and opportunity management is not just a periodic process, but should take place continuously as all actions may carry a risk aspect.

\subsection{ISO 31000 and IEC 62198}

International Organization for Standardization covers the risk management as well with family of standards ISO 31000. ISO 31000 itself covers the principles and general guidelines. It provides a universally recognized paradigm for practitioners. IEC 62198 provides principles and generic guidelines on managing risk and uncertainty in projects. In particular it describes a systematic approach to managing risk in projects based on ISO 31000, Risk management - Principles and guidelines. Guidance is provided on the principles for managing risk in projects, the framework and organizational requirements for implementing risk management and the process for conducting effective risk management. Furthermore, ISO/IEC 31010 describes individual risk assessment techniques. Most of this subchapter is made up of quotations from ISO (2009) and IEC (2013).

The overview schema of guidelines is shown on Fig. 5. We can see that process design for risk management is similar in all literature sources.

\subsubsection{Communication and consultation}

Communication and consultation with stakeholders is important as they make judgements about risk based on their perceptions. These perceptions can vary due to differences in values, needs, assumptions, concepts and concerns of stakeholders. As their views can have a significant impact on the decisions made, the 'stakeholders' perceptions should be identified, recorded, and taken into account in the decision-making process. Organisations should consider using appropriate methods based on the information needs of the stakeholders. Communication and consultation with appropriate external and internal stakeholders should take place within all steps of the risk management process. The most effective consultation starts early and continues throughout the risk management process.

Communication and consultation should facilitate truthful, relevant, accurate and understandable exchanges of information, taking into account confidential and personal integrity aspects. Effective external and internal communication and consultation should take place to ensure that those accountable for implementing the risk management process and stakeholders understand the basis on which decisions are made, and the reasons why particular actions are required.

\subsubsection{Establishing the context}

Risk only exists in the context of objectives. It is essential for the organization to understand the internal and external context related to its objectives, and the associated factors that give rise to uncertainties. While many of these factors are similar to those considered in the design of the risk management framework, when establishing the context for the risk management process, they need to be considered in greater detail and particularly how they relate to the purpose and scope of applying the risk management process. Failure to adequately capture the context can affect conclusions and decisions in other steps of the process.

The external context is the external environment in which the organization seeks to define and achieve its objectives. Understanding the external environment is important in order to ensure that the external sources of risk are identified and perspectives of external stakeholders are considered. It is based on the organization-wide 
context, but tailored to the purpose and scope of the process.

The internal context is the internal environment in which the organization seeks to define and achieve its objectives. For project risk management it means context of the project and achievement of project goals.

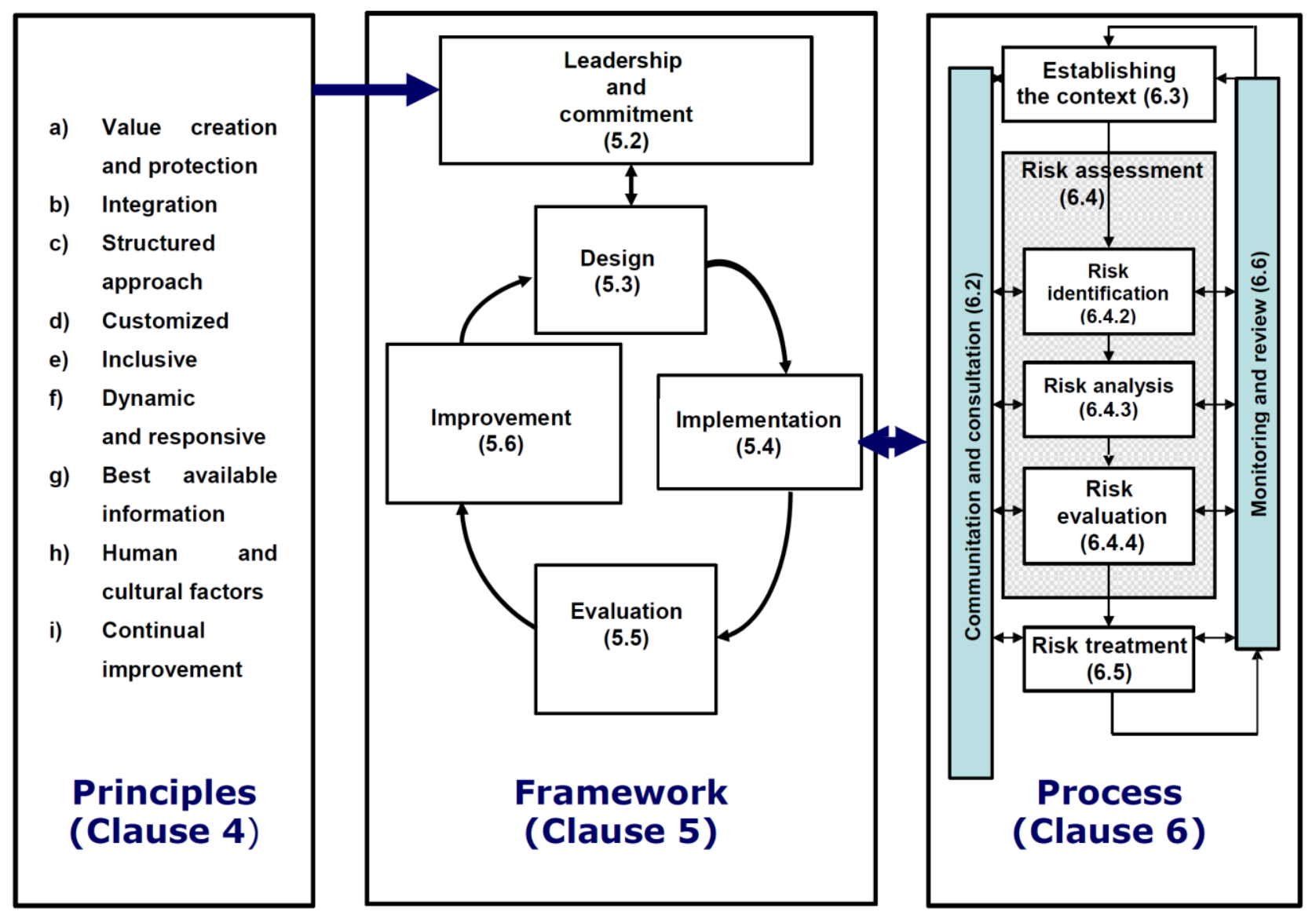

Fig. 5: ISO 31000: Relationship between the principles, framework and process (ISO, 2009)

\subsubsection{Risk identification}

The purpose of risk identification is to identify uncertainties and their range of possible effects (i.e. consequences) on project objectives. Identification of uncertainties and their effects may result in update to risk criteria and/or update to the purpose and scope of the process. To ensure that as far as possible all risks that matter to projects objectives are identified, risk identification should be conducted systematically, iteratively, knowledgeably and collaboratively, drawing on the knowledge and views of stakeholders. It should use best available information supplemented by further enquiry as necessary.

If risks are not identified within this step, they will not be included in further analysis, which may result in incorrect or incomplete understanding of risks. Project team should also identify any existing risk treatments related to the risks identified in this step, as they may also facilitate in developing understanding on identified risks.

\subsubsection{Risk analysis}

The purpose of risk analysis is to extend the understanding of the risk developer in the risk identification step, providing some measure of the magnitude of risk. Therefore risk analysis provides an input to risk evaluation and to decisions on whether and how risks need to be treated and on the most appropriate risk treatment strategies and methods. Risk analysis involves detailed assessment of uncertainties, risk sources, events and scenarios and their positive and negative consequences along with their likelihood. There may be multiple consequences with several objectives or assets affected or a range of magnitudes of consequence possible.

Where there is a range of consequences which can be quantified this can be displayed as a probability distribution. Descriptive or numerical information about possible consequences under different circumstances can be obtained through modelling from available data or experiments. Consequences can be described in terms of tangible or intangible effects.

Risk analysis involves applying one or more techniques to measure the risks captured in the risk identification step. The techniques can be based on qualitative and/ or quantitative methods. The techniques used and the means of measurement should be harmonized, where appropriate, so risk analysis outputs can be aggregated and compared. 


\subsubsection{Risk evaluation}

The purpose of risk evaluation is to decide whether a risk is acceptable or unacceptable to the organisation in relation to its objectives. This involves comparing the level of risk found during the analysis process with the previously defined risk criteria. Based on this comparison treatment should be considered. Decisions should take into account the wider context of the risk and include consideration of the risks borne by other parties. This includes legal, regulatory and other requirements.

If applicable both positive and negative consequences should be considered in risk evaluation. In such situations, evaluation should be made based on risk criteria with a view to achieve the projects objectives. In some circumstances, the risk evaluation can lead to a decision to undertake further analysis. The risk evaluation can also lead to a decision not to treat the risk in any way other than maintaining existing controls.

If it is decided in the course of risk evaluation that the risk should be accepted without modification, it will be appropriate to record this decision so that it can be subjected to ongoing review.

\subsubsection{Risk treatment}

Risk treatment involves selecting one or more options for responding to risks, and implementing those options.

Risk treatment options are not necessarily mutually exclusive or appropriate in all circumstances. Options for treating risk involve one or more of the following:

- avoiding the risk by deciding not to start or continue with the activity that gives rise to the risk;

- taking or increasing the risk in order to pursue an opportunity;

- removing the risk source;

- changing the likelihood;

- changing the consequences;

- sharing the risk with another party or parties through contracts;

- risk financing (internally e.g. retention, or transfer e.g. buying insurance);

- retaining the risk by informed decision.

Selecting the most appropriate risk treatment option involves balancing the benefits derived in relation to the achievement of the objectives against any costs, effort, or disadvantages of implementation. Justification for risk treatment may be broader than economic considerations and take into account all obligations and commitments of the organization. The selection of risk treatment options should be made in accordance with the project's and organizations objectives and risk criteria. When selecting risk treatment options, the project team should consider the values and perceptions of stakeholders and the most appropriate ways to communicate and consult them. Where risk treatment options can affect internal or external stakeholders, they should be involved in the decision.

Even if carefully designed and implemented, risk treatments might not have the effect assumed. It can also create unintended consequences inside or outside the project. Monitoring needs to be an integral part of the risk treatment implementation to give assurance that the treatments remain effective. Risk treatment can also introduce new risks that need to be assessed, treated, monitored and reviewed. These new risks should be incorporated into the same treatment plan as the original risk and not treated as a new risk. The link between the two risks should be identified and maintained.

\subsubsection{Monitoring and review}

Monitoring and review should be part of the core risk management process and involve checking or surveillance with ongoing oversight by top management and those with delegated authority. Responsibilities for monitoring and review should be clearly defined. The project's monitoring and review processes should encompass all aspects of the risk management process and they may include the use of indicators and alerts.

Progress in implementing risk treatment plans provides a performance measure. The results can be incorporated into the project's overall performance management, measurement and external and internal reporting activities. The results of monitoring and review should be recorded and externally and internally reported as appropriate, and should also be used as an input to the review of the risk management framework.

\section{Comparison of standards for risk management}

In the chapter 3 there was provided an overview of most known world standards for risk management methods. Although the standards are similar in its core, there are some differences if we look into the details. First, let's compare the process of individual standards.

In the Table 2 there is comparison of the processes of selected standards. The core parts of the processes in all standards are identifying risks; risk analysis, plan risk responses and control risks (although in different standards the names of process phases have different names).

PMI and IPMA have as first step of the process plan of risk management / develop risk management framework. On the other hand, PRINCE2 and ISO 31000 / IEC 62198 have identified / establish context. Same two standards include communication as part of the risk management process, whereas PMI and IPMA don't have communication emphasised as the part of the process. 
Concerning risk analysis, only PMI separates analysis into qualitative analysis and quantitative analysis. IS0 31000 / IEC 62198 separates analysis phase into risk analysis and risk evaluation. Other two standards have analysis only as one step although in the details they are mentioning both qualitative and quantitative techniques.
In my opinion, definitely formal planning of risk management approach and explicit mentioning of communication as part of the process has added value in overall design of risk management process (Rehacek, 2014). Both steps should be part of ideal risk management process.

Table 2: Comparison of risk management processes

\begin{tabular}{|c|c|c|c|c|}
\hline PMI PMBOK & $\begin{array}{c}\text { PRINCE2 } \\
\text { (based on MoR) }\end{array}$ & IPMA (ICB 4.0) & $\begin{array}{c}\text { ISO } 31000 \text { / IEC } \\
62198 \\
\end{array}$ & ISO 21500 \\
\hline $\begin{array}{c}\text { Plan Risk } \\
\text { Management }\end{array}$ & \multirow{2}{*}{$\begin{array}{c}\text { Identify } \\
\text { (Context and Risks) }\end{array}$} & \multirow{2}{*}{$\begin{array}{l}\text { Develop and implement a risk } \\
\text { management framework } \\
\text { Identify risks and } \\
\text { opportunities }\end{array}$} & $\begin{array}{l}\text { Establishing the } \\
\text { Context }\end{array}$ & \\
\hline Identify Risks & & & Risk Identification & Identify Risks \\
\hline $\begin{array}{l}\text { Perform Qualitative } \\
\text { Risk Analysis } \\
\text { Perform Quantitative } \\
\text { Risk Analysis }\end{array}$ & $\begin{array}{l}\text { Assess } \\
\text { (Estimate and } \\
\text { Evaluate) }\end{array}$ & $\begin{array}{l}\text { Assess the probability and } \\
\text { impact of risks and } \\
\text { opportunities }\end{array}$ & $\begin{array}{l}\text { Risk analysis } \\
\text { Risk evaluation }\end{array}$ & Assess risks \\
\hline Plan Risk Responses & Plan & $\begin{array}{l}\text { Select strategies and } \\
\text { implement response plans to } \\
\text { address risks and } \\
\text { opportunities }\end{array}$ & Risk treatment & Treat Risks \\
\hline \multirow[t]{2}{*}{ Control Risks } & Implement & \multirow[t]{2}{*}{$\begin{array}{l}\text { Evaluate and monitor risks, } \\
\text { opportunities and } \\
\text { implemented responses }\end{array}$} & $\begin{array}{l}\text { Monitoring and } \\
\text { Review }\end{array}$ & Control Risks \\
\hline & Communicate & & $\begin{array}{l}\text { Communication and } \\
\text { Consultation }\end{array}$ & \\
\hline
\end{tabular}

Another comparison can be made for approach of planning risk responses. Summary is elaborated in Table 3 ( $\mathrm{T}$ means threat and 0 opportunity in first column of the table). All standards except ISO 31000 take into account both threats and opportunities. ISO 31000 focus mainly on threats when discussing risks, but IEC 62198 mention consistently both threat and opportunity when planning risk responses. Types of responses are similar in all standards. PRINCE2 and IPMA mention implementation of contingency plan (or fall-back) as type of response strategy.

Ideal and modern risk management process should definitely treat both risks and opportunities. On the other hand, the contingency plan seems to be not necessary to mention as basic risk response strategy. In fact, it is plan which can be used for any risk response strategy which can result with impact on project objectives. For example combination with mitigate or accept response is quite reasonable.

Table 3: Comparison of risk responses

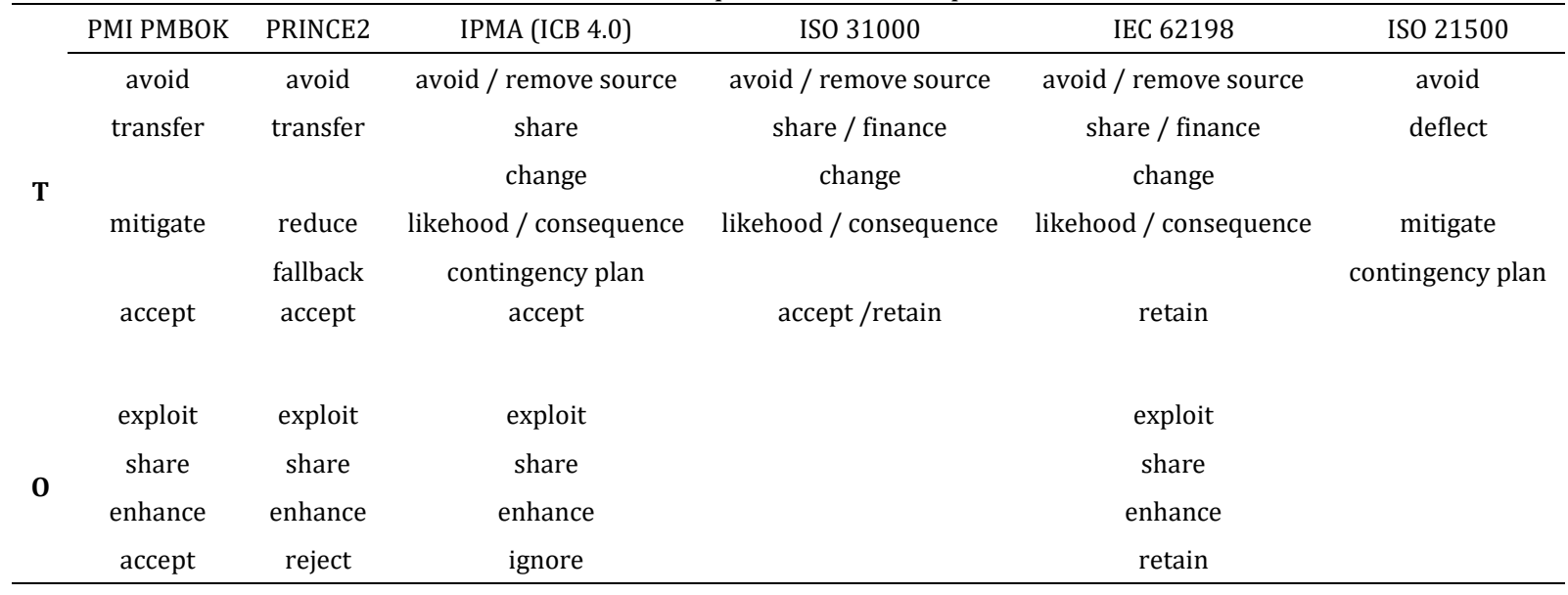

Concerning individual qualitative and quantitative techniques for risk analysis, the level of detail is various in individual standards. Some standards describes techniques with great detail for example ISO 31000 refers to the additional standard ISO 30010 which contains detailed description of many techniques, PMI PMBOK summarizes some of techniques into detail as well, while PRINCE2 and IPMA contains only general references for useful techniques and leaves further study completely to the reader. It is obvious, that some tools and techniques are suitable more for different kind of businesses - production or manufacturing is different than healthcare or retail for example. Selection of appropriate tools and techniques for the risk management process is important factor of tailoring for purpose of the project, organization or both.

An organization or business unit which wants to implement project risk management or generally 
risk management will not make a mistake choosing any of these standards and inspiration. Tweaking according to context of organization or maturity of project management will be definitely wise, so final framework is tailored exactly to fit given organization.

\section{Conclusion}

In the previous chapters, the concept of risk and risk management was recapitulated followed by brief but complete description of project risk management process in most known world standards for risk management: PMI PMBOK, PRINCE2, IPMA, ISO 31000 and IEC 62198.

Comparison of process phases of individual processes and risk response strategies was performed. Result of comparison showed that although all world standards have similar core of the risk management process, some differences exists.

Therefore, if an organization wants to implement own risk management process or framework inspired by world known best practice, it could be useful to look on more than just one standard and tailor suitable combination based on own needs.

As was as well shown, up-to-date methodology of treating risks must count not only with treat but as well with opportunity, when dealing with risks. All standards recommend plenty of tools and techniques for risk analysis; especially ISO 31010 (IEC/ISO, 2009) provides very broad and detailed description of such techniques.

Again, an organization implementing project risk management should pick such tools and techniques from whole range of them which suits well the context of whole organization, while leaving some space to tailor project risk management according to project context for project manager in charge of given project.

\section{References}

IEC (2013). Managing risk in projects - Application guidelines. IEC 62198, International Electrotechnical Commission, Geneva, Switzerland.

IEC/ISO (2009). Risk Management-Risk assessment techniques. IEC/ISO 31010. International Organization for Standardization. Geneva, Switzerland.

IPMA (2015). IPMA Individual competence baseline for project, programme and portfolio management. International Project Management Association. Available online at: http://products.ipma.world/wp-content/uploads/2016/03/ IPMA_ICB_4_0_WEB.pdf

ISO (2009). Risk management - Guidelines. ISO 31000, International Organization for Standardization. Geneva, Switzerland.

OGC (2009). Managing successful projects with PRINCE2. Office of Government Commerce, London, UK.

PMI (2009). Practice standard for project risk management. Project Management Institute, Atlanta, USA. Available online at: https://www.pmi.org/pmbok-guide-standards

PMI (2013). A guide to the project management body of knowledge (PMBOK Guide). Project Management Institute, Atlanta, USA. Available online at: https://www.pmi.org/ pmbok-guide-standards

Rehacek P (2011). Risk management and FMEA. In the $9^{\text {th }}$ International Conference on Strategic Management and its Support by Information Systems. Celadna, Czech Republic: 154-158.

Rehacek P (2014). Standard ISO 21500 and PMBoK® guide for project management. International Journal of Engineering Science and Innovative Technology, 3(1): 2998-295.

Šviráková E (2014). System dynamics methodology: Application in project management education. In the International Conference on Efficiency and Responsibility in Education, TBU Publications, Czech University Life Sciences Prague, Prague, Czech Republic: 813-822. Available online at: https://publikace.k.utb.cz/handle/10563/1004238

Šviráková E and Soukalová R (2015). Creative project management: Reality modelling. In the Innovation Vision 2020: From Regional Development Sustainability to Global Economic Growth, International Business Information Management Association (IBIMA), Amsterdam, Netherlands, 1: 1085-1097. Available online at: https://publikace.k.utb.cz/ handle/10563/1005704 